\title{
REVOLUÇÃO E POESIA EM O NOME DAS COISAS DE SOPHIA DE MELLO BREYNER ANDRESEN
}

Rodrigo Corrêa Martins Machado*

RESUMO: Sophia de Mello Breyner Andresen figura como uma das mais significativas poetas da Literatura Portuguesa Contemporânea. Em relação à escrita poética andreseniana, na lírica, a artista buscou o estabelecimento de uma relação com o real através das palavras, com inegáveis influências clássicas que se devem, principalmente, à paixão da poeta pela cultura grega. Destacamos, na escrita de Sophia, a forte relação entre poesia e os problemas sociopolíticos, uma vez que ela se mostrou totalmente contrária às injustiças cometidas durante a ditadura em Portugal, de maneira a se tornar um dos grandes expoentes de resistência ao governo totalitário. Nesse trabalho objetivamos estudar as aproximações existentes entre Poesia e História na obra andreseniana $O$ nome das Coisas (1977). Nessa obra, deparamos-nos com poemas de reflexão profunda em relação ao tempo passado, presente e, sobretudo, ao tempo futuro que, naquele momento, afigurava-se como algo libertador, no qual haveria liberdade para sonhar, se expressar e para resgatar a grandeza de Portugal, que há muito havia se perdido.

PALAVRAS - CHAVE: Poesia; História; Memória; O Nome das Coisas; Sophia de Mello Breyner Andresen.

ABSTRACT: Sophia de Mello Breyner Andresen figure as one of the most significant poets of Contemporary Portuguese Literature. Regarding andreseniana poetic writing, in lyric, the artist sought to establish a relationship with reality through words, undeniable classical influences, mainly due to the poet's passion for Greek culture. We highlight the writing of this poet, the strong relationship between poetry and the social-politics. Since it proved to be totally contrary to the injustices committed during the dictatorship in Portugal, in order to become one of the great exponents of resistance to totalitarian government. In this work we aimed to study the approaches between Poetry and History in the work andreseniano O Nome das Coisas (1977). In this work, we encounter poems of deep reflection about the past, present and especially future time, at that time, it seemed as something liberating, in which there would be freedom to dream, to express themselves and to reassert the greatness of Portugal, which had long been lost.

KEYWO RDS: Poetry; History; Memory; O Nome das Coisas; Sophia de Mello Breyner Andresen.

Sabemos que a vida não é uma coisa e a poesia outra. Sabemos que a politica não é uma coisa e a poesia outra. Procuramos o coincidir do estar e do ser. Procurar a inteireza do estar na terra é a busca da poesia (ANDRESEN, 1977, P. 78).

Ao tratar-se de trabalhos de Literatura Comparada referentes à aproximação entre Literatura e História, a maioria dos estudos elaborados debruça-se sobre essa relação estudando-a no gênero literário romance. No que diz respeito a essa comparação utilizando-se o gênero lírico como base, escassos são os estudos e os estudiosos que se propuseram a pensá-la.

Uma possível explicação para não se utilizar a lírica na comparação com a História é a dificuldade que há entre aproximações entre um gênero em prosa e outro em versos. Além disso, os estudiosos da História, principalmente a partir do século XIX, tendiam a 
considerar essa disciplina relativa ao campo das ciências. O que a tornaria, portanto, isenta de qualquer subjetividade, elemento identificador dos discursos literários em geral, com destaque para a poesia, tida como uma visão particular do Eu em relação ao mundo.

Alguns estudiosos como José Guilherme Merquior (1997), apesar de não problematizarem a questão, não deixaram de entrever em seus estudos a utilização do elemento histórico para a construção de poesia. Tal estudioso assinala que

Frequentemente, o que nos impede de enxergar no poema a abertura ao mundo histórico, sem cair na mutilação documental, são preconceitos derivados do quase monopólio mantido entre as ideologias artísticas, no que concerne às relações significativas entre literatura e sociedade, pela concepção realista, formada no século passado em torno do romance de 1830. (MERQUIOR, 1997, p. 31).

Os estudos literários até então desenvolvidos deixaram na sombra a grande capacidade de alusão ao mundo histórico, típica de grandes obras líricas, como em Ilíada, Odisséia, Eneida, Os Lusíadas, Mensagem, dentre outras.

Como aponta Merquior (1997), nem mesmo na narrativa em si, o foco reside na matéria histórico-empírica. O que não quer dizer que não haja ali referências diretas ao mundo concreto e real na qual a narrativa se espelha. Também Sophia de Mello Breyner Andresen não vislumbra uma relação distanciada do poema com a vida e a História. Ela admite, de maneira clara, como observa-se na epígrafe deste trabalho, que seus poemas são todos diretamente relacionados à vida e à condição humana, não há como pensá-los e analisá-los de outra forma. Ela diz buscar a coincidência existente entre o ser e sua capacidade de estar, de viver e, porque não, vivenciar, reconhecendo que a lírica é uma forma privilegiada de representar dado momento histórico vivido pelo ser humano.

Ao questionar-se a representação factual na lírica, perguntas se sobrepõem no que diz respeito também ao fazer História, na medida em que, ao considerar-se o fazer histórico somente a partir de consulta e utilização de informações contidas em documentos, dá-se a essa construção um aspecto consideravelmente redutor. Qualquer escrito tido por estudiosos como documento é também passível de desconstrução no que diz respeito à sua objetividade, já que foi redigido por um Eu particular, possuidor de ideologias, crenças, que, por conseguinte, de maneira alguma estaria isento de subjetividade. Hayden White (1994) afirmou que os historiadores encontravam (e encontram) documentos que falam sobre o mesmo assunto, e entre esses documentos há lacunas, há falhas preenchidas pelo 
estudioso. Por trás desse preenchimento, há sempre uma pessoa com crenças, preconceitos e ideologias que os coloca em seu texto mesmo que implicitamente.

Existe o reconhecimento de que a História é uma indagação e, de certa forma, representação dos acontecimentos relacionados ao ser humano. Por um lado, deve-se ter em mente que os resultados dos estudos historiográficos são parciais, uma vez que são diretamente comprometidos com aquele que produziu o discurso e com o público ao qual se destina (BURKE,1992).

Por outro lado, a ficção também consiste numa busca de verdade, do conhecimento sobre a experiência do ser humano com o presente e o passado. No entanto, o que a diferencia da História é a liberdade de criação - a literatura é muito mais livre para inventar -, a essência da sua escrita é inegavelmente a imaginação, a criação de mundos e de histórias diferentes das convencionadas por historiadores ou quaisquer outras pessoas (LIMA, 1989). A literatura é diretamente oposta à pretensa visão clara e objetiva da ciência.

O historiador e o literato têm em seus textos várias possibilidades diferentes de interpretação, eles agem como críticos dos seus discursos. Enquanto o escritor de literatura muitas vezes nos aponta várias direções, o historiador liberta-se de algumas possibilidades visionais e foca somente em uma, naquela em que ele mais identifica seus valores, que julga ser a "verdadeira" - ele seleciona qual documento se identifica mais com o discurso que pretende elaborar. Podemos notar que o discurso histórico nada mais é que um "discurso figurativo" moldado por seus estudiosos.

O que difere o discurso historiográfico do ficcional é o foco narrativo, enquanto a História tem o compromisso com a busca da verdade e se restringe a relatos do passado, a literatura não aceita nenhuma amarra, é mais livre para criar, para decidir sobre o que falar, ela fundamenta um mundo onde a imaginação prevaleça. Discursos próximos, o do historiador e do escritor literário, porém suas narrativas se diferenciam quando o ponto é o relacionamento destas com o mundo e o modo como atua o narrador neste (LIMA, 1989).

Ao relacionarmos literatura e história, devemos ter em mente que esta é feita também pelos homens que nem sempre figuram em documentos, nem mesmo expõem sua visão através da escrita. Fazer história também consiste em vivê-la e deixar à posteridade impressões de um Eu o qual vivenciou o que se passava em seu tempo, o que aponta para o fato de que se pode elaborar um discurso histórico através da ficção.

Seja como for, desejamos investigar as relações existentes entre os poemas elaborados pela poeta portuguesa Sophia de Mello Breyner Andresen e a História, 
destacando-se, neste caso, tal relacionamento na obra O Nome das Coisas (1977). Esta obra foi escrita durante os últimos anos da ditadura vigente em terras portuguesas - chamada Salazarismo, em alusão a António Oliveira Salazar, seu fundador e líder - à Revolução que deu fim ao regime absolutista e os anos iniciais de liberdade em relação a tal regime totalitário.

No tocante à escrita andreseniana, devemos destacar que ela se abre à intertextualidade, considerando-se que nela “[...] a 'palavra literária' não é um ponto (um sentido fixo), mas um cruzamento de superfícies textuais, um diálogo de diversas escrituras: do escritor, do destinatário (ou da personagem), do contexto cultural atual ou anterior" (KRISTEVA, 1974, p. 62). Grande parte dos poemas escritos por Sophia configura-se, realmente, como cruzamento de várias superfícies textuais, colocando em relevo toda a discussão empreendida pela autora concernente ao contexto histórico, político e cultural da época em que foram escritos.

Para entendermos melhor a escrita poética, político e historicamente engajada, de Sophia Andresen, devemos, primeiramente, relembrarmos que tal mulher, nascida em 1919, vivenciou, em Portugal, a partir de 1933, um estado ditatorial que teve duração de 41 anos (deposto em abril de 1974). Nesse regime, duas entidades caracteristicamente dominadoras, Estado e Igreja, uniram-se a fim de controlar todas as esferas da vida portuguesa e, para isso, utilizaram-se de mecanismos como a censura e a opressão, que obrigavam a todos os cidadãos a se submeterem a tal política.

A poeta mostrou-se totalmente contrária às injustiças cometidas pelo Estado salazarista, de maneira a tornar-se um dos grandes expoentes de resistência ao governo. Tal aspecto pode ser observado pelo fato de ela ter sido uma das fundadoras da Comissão Nacional de Socorro aos Presos Políticos, de ter, em seus poemas, escrito contra a guerra colonial entre Portugal e as colônias africanas, além de em 1975 ter sido eleita como deputada para a Assembléia Constituinte, pelo Partido Socialista Português.

O Nome das Coisas (1977) figura dentre uma das principais obras de reflexão acerca do período ditatorial português e, principalmente, sobre a Revolução dos Cravos, a qual foi anunciada e feita inicialmente pelos militares portugueses descontentes com o regime e que obteve adesão popular, a fim de depor o regime totalitário. Nessa obra, deparamos- nos com poemas de profunda reflexão relacionados ao tempo passado, presente e, sobretudo, ao tempo futuro que, após a revolução, a figurava-se como algo libertador, no qual haveria novos caminhos para sonhar, se expressar e para resgatar a grandeza de Portugal, que há 
muito havia se perdido. Além disso, Sophia, na obra em questão (principalmente, nos poemas datados a partir de 1975), não deixa de assinalar certo sentimento de tristeza ou mesmo de desilusão quanto à revolução, uma vez que, ao referir-se a essa revolta, ela diz "Do quebrado projecto de sua empresa em ruína" (ANDRESEN, 1977, p. 58).

Leyla Perrone-Moisés (1978, p. 63) assinala que “Todo texto é absorção e transformação de uma multiplicidade de textos', diz Kristeva, na esteira de Bakhtin. Entende-se por intertextualidade este trabalho constante de cada texto em relação aos outros, esse imenso e incessante diálogo entre obras que constitui a literatura". A obra andreseniana em relevo faz não somente um diálogo com o gênero lírico em si, mas também com as relações sociais, políticas e históricas vivenciadas por um Eu particular, refletindo indiretamente a angústia, a percepção do mundo no qual milhões de pessoas viviam.

Theodor Adorno (2003, p. 74) ressalta que "o pensar sobre a obra de arte está autorizado e comprometido a perguntar concretamente pelo teor social”. Isso, porque segundo este estudioso, "Só entende aquilo que o poema diz quem escuta, em sua solidão, a VOz da humanidade; mais ainda, a própria solidão da palavra lírica é pré-traçada pela sociedade individualista".

Há que se considerar, dessa maneira, que Sophia Andresen, portuguesa, mulher que vivenciou períodos críticos como a Guerra Colonial, abuso de poder por parte do Estado com ajuda da Igreja e 33 anos de ditadura, ao transcrever para a lírica seus sentimentos individuais, transpôs para o poema sentimentos de toda a população que com ela compartilhava tais amarguras. Ela se faz universal por preocupar-se com problemas socais portugueses e, consequentemente, das ex-colônias portuguesas na África, como também por revelar ao mundo uma agonizante luta pela liberdade de viver, de sentir e de se expressar.

"Uma corrente subterrânea coletiva é o fundamento de toda lírica individual", dessa forma "a substancialidade da lírica individual deriva essencialmente de sua participação nessa corrente subterrânea coletiva", pois ela possibilita que o sujeito expresse sua voz através da linguagem (ADORNO, 2003, p. 77). A lírica tem a possibilidade de antecipar uma situação a qual, por mais que represente aparentemente o individual, transpõe-no.

A própria Sophia atribui à poesia um relevante papel na sociedade, uma vez que ela afirma: 
É a poesia que desaliena, que funda a desalienação, que estabelece a relação inteira do homem consigo próprio, com os outros e com a vida, com o mundo e com as coisas. E onde não existir essa relação primordial limpa e justa, essa verdade das coisas, nunca a revolução será real (ANDRESEN, 1977, p. 78).

A partir dos poemas tecidos em O Nome das Coisas existe a possibilidade de diálogo com o período histórico, com o sofrimento de um povo e a agonia de uma pátria que até então se pensava Império. A linguagem poética nesse texto é multideterminada, possui uma ampla gama de leituras, dirige-se a vários textos e contextos.

Os poemas que compõem o livro em questão revelam-se intervenientes e atentos aos problemas sociais. Considerando-se que a autora dessa obra teve uma atuação cívica relevante em relação à oposição ao regime salazarista e à defesa das liberdades, o caráter combativo de sua obra pode ser vislumbrado no poema "Revolução":

\author{
Como casa limpa \\ Como chão varrido \\ Como porta aberta \\ Como puro início \\ Como tempo novo \\ Sem mancha nem vício \\ Como a voz do mar \\ Interior de um povo \\ Como página em branco \\ Onde o poema emerge \\ Como arquitectura \\ Do homem que ergue \\ Sua habitação \\ (BREYNER, 2004, p. 229).
}

Tal poema, escrito dois dias após o 25 de Abril de 1974 (Revolução dos Cravos), reflete o sentimento de renovação que perpassou grande parte dos lusitanos que se libertou das amarras de um regime totalitário e repressivo. A autora faz uma reflexão sobre a maneira que o país se encontrava perante a nova situação "Como casa limpa", "Sem mancha nem vício", "Como página em branco", como um lugar que se mostra renovado, "varrido" dos vícios que o proibiram por certo tempo de caminhar, de mostrar sua voz, lutar por seus direitos. A força lírica ressalta uma nova situação emergente, é como se a 
Revolução sorrisse para Portugal, apontando-lhe novas possibilidades que surgiriam a partir daquele momento.

Os poemas andresenianos são verdadeiras memórias dos períodos vividos antes, durante e após a Revolução de Abril. Eles abrangem não somente o período tenso anterior à revolta como também o sentimento e pensamento utópicos surgidos logo após o 25 de abril, além do período marcado pelo fim da utopia, já que nem todas as realizações esperadas com o fim da ditadura foram realizadas. Há reflexões maduras referentes ao período pós-utopia, o qual a pátria e sua população enfrentavam, apresentando erros, acertos, enfim, revelando de maneira crítica aquilo que deveria ser seguido, além do que deveria ser mudado. Observa-se essa relação reflexiva no poema "Projecto":

Esta foi sua empresa: reencontrar o limpo

Do dia primordial. Reencontrar a inteireza

Reencontrar o acordo livre e justo

E recomeçar cada coisa a partir do princípio

Em sua empresa falharam o relato

De sua errância erros e derrotas

De seus desencontros e desencontradas lutas

É moroso e confuso

Porém restam

Do quebrado projecto de sua empresa em ruína

Canto e pranto clamor palavras sem harpas

Que de geração em geração ecoam em contínua memória de um projecto Que sem cessar de novo tentaremos.

(ANDRESEN, 1977, p. 58).

Percebe-se que o eu lírico andreseniano aponta em "Projecto" para o fato de ter havido uma concepção que, de início, gostaria de restaurar a "inteireza" da pátria e de seus filhos. Aproveitando-se de certo furor diante da revolução, a ideia inicial seria retornar ao dia em que existiam liberdade e justiça, sem deixar de atentar para o desejo de “(...) recomeçar cada coisa a partir do princípio”. Entretanto, tal projeto falhara, apresentara derrotas, anseios, pensamentos altamente divergentes, que em muitos momentos destituíram-no de sua identidade primordial.

O sujeito poético não deixa de questionar o verdadeiro valor desse projeto arruinado. Ao mesmo tempo, ele alicerça o presente e o futuro nas errâncias, já que os erros proporcionaram ensinamentos aos que executaram o plano inicial. Ao proferir "Que sem cessar de novo tentaremos", o eu lírico representa uma humanidade que por ele é 
representada, um contingente humano que, apesar das derrotas, não desistirá da luta e que, devido aos tropeços anteriores, fará as coisas de maneira distinta, com um olhar mais amadurecido e menos utópico.

A construção da memória e a discussão de problemas sociopolíticos na poesia de Sophia não deixam de referir-se ao futuro como algo distante que, concomitantemente a esse distanciamento, precisa ser vislumbrado desde já. Atingir a um mundo em que o nome e as coisas devem estar obrigatoriamente em consonância não é algo simplificado, mas que deve estar em busca constante, uma vez que quanto maior for o grau de proximidade entre esses elementos, a humanidade estará mais iminente de viver em um mundo limpo, justo, livre, no qual os seres preocupar-se-ão em realizar sua alteridade em plenitude. Dentro desse aspecto, é inconcebível a não apresentação de "A forma justa":

Sei que seria possível construir o mundo justo

As cidades poderiam ser claras e lavadas

Pelo canto dos espaços e das fontes

O céu o mar e a terra estão prontos

A saciar a nossa fome do terrestre

A terra onde estamos - se ninguém atraiçoasse - proporia

Cada dia a cada um a liberdade e o reino

- Na concha na flor no homem no fruto

Se nada adoecer a própria forma é justa

E no todo se integra como palavra em verso

Sei que seria possível construir a forma justa

De uma cidade humana que fosse

Fiel à perfeição do universo

Por isso recomeço sem cessar a partir da página em branco

E este é meu ofício de poeta para a reconstrução do mundo (ANDRESEN, 1977, p. 70).

Como dito anteriormente, o eu lírico andreseniano é enfático quanto à possibilidade de edificar-se um mundo justo, no qual "As cidades poderiam ser claras e lavadas". Devemos ressaltar a metáfora da claridade na poesia de O Nome das Coisas, pois ela é utilizada para referir-se à construção de um mundo, estabilização de um locus no qual o Eu possa ser livre, limpo de quaisquer desejos de subjugar o Outro a seus valores próprios. A claridade reprime qualquer pensamento e ações obscuras que possam ter sido advindas de regimes totalitários e excludentes em todo o mundo, que causaram desentendimentos, intolerância e guerras entre povos que devem saber aproveitar "O céu o mar e a terra". Ademais, tal elemento pode relacionar-se também à ideia de esclarecimento, algo necessário 
a todos para usufruírem de maneira igualitária do mundo, de proporcionar "Cada dia a cada um a liberdade e o reino".

Digna de um verdadeiro esteta, que a cada modo de conceber a vida como imperfeita busca a criação de um locus em que seja vigente o conceito de perfeição, a escrita de Sophia Andresen busca "construir a forma justa/ De uma cidade humana que fosse/ fiel à perfeição do universo". Como aponta Fernando Pessoa (1980, p. 8) "Este ideal de perfeição é o ideal helénico, ou o que pode assim designar-se, por terem sido os gregos antigos quem mais distintamente o teve, quem em verdade, o formou, de quem, por certo, ele foi herdado pelas civilizações posteriores".

Seguindo claramente o ideal helênico, Sophia busca "recomeçar sem cessar a partir da página em branco". O branco da página também relaciona-se ao ideal de claridade buscado na poética andreseniana, como um lugar estático, proporcionador da tentativa de edificar-se um plano perfeito. Para tanto, Sophia incumbe a si própria o dever de poeta enquanto alguém que através da escrita empreende uma reconstrução do mundo, algo que um seguidor do ideal helênico jamais deixará de fazer, a não ser quando houver uma união perfeita entre ser humano e universo, entre o nome e as coisas.

A discussão empreendia até o presente momento quanto ao estudo das intersecções existentes entre discurso poético e histórico mostra-se altamente produtiva, uma vez que, ao tecer a lírica, qualquer poeta reflete em seu trabalho a sociedade a que pertence, as crenças de seu povo, bem como determinado período histórico. Como apontado por Maurice Halbwachs (2006), qualquer indivíduo participa simultaneamente de dois tipos de memória, a individual e a coletiva. Individual, no sentido de que suas lembranças têm lugar no contexto de sua personalidade ou de sua vida pessoal; e coletiva, considerando-se que ele se comporta como pertencente a determinado grupo, com o qual contribuiu evocando e mantendo lembranças impessoais.

O estabelecimento de relações que confirmem a escrita como uma forma de evocar e manter as lembranças é observado também na composição poética, nela "as lembranças coletivas viriam a se aplicar sobre as lembranças individuais" (HALBWACHS, 2006, p. 80 ). Desta forma, “[...] é da própria lembrança, em torno dela, que vemos de alguma forma raiar seu significado histórico” (HALBWACHS, 2006, p. 82 ).

A respeito dessa intersecção entre textos literários e históricos, Paul Ricoeur (2010), considera e admite a "capacidade desdobrada" da literatura de não só registrar e 
ficcionalizar os fatos históricos concernentes à vida dos povos, mas também de, na plenitude de sua potencialidade ficcional, "fazer história".

Seja como for, há um inegável destaque para a relação intertextual entre os discursos histórico e literário, uma vez que a intertextualidade assinala que os meios de expressão e os mecanismos organizadores da ficção são os mesmos que instrumentalizam História. Por se constituírem como constructos linguísticos, História e ficção apresentam-se como gêneros permeáveis, convencionados em suas formas.

\section{REFERÊNCIAS:}

ADORNO, Theodor W. Palestra Sobre lírica e sociedade. In: ADORNO, Theodor W. Notas de Literatura I. Trad. Jorge M B de Almeida. Ed. 34. São Paulo: Duas Cidades. 2003.p. $65-89$.

ANDRESEN, Sophia de Mello Breyner. O Nome das Coisas. Lisboa: Moraes editores, 1977.

Revolução e Política. In: ANDRESEN, Sophia de Mello Breyner. O nome das coisas. Lisboa: Moraes editores, 1977, pp. 77 - 80

Obra Poética. 2a ed. Alfragide: Caminho, 2011.

BURKE, Peter. A Escrita da História. Trad. Magda Lopes. São Paulo: Editora da UNESP, 1992.

HALBWACHS, Maurice. Memória coletiva e memória histórica. In: HALBWACHS, Maurice. A memória coletiva. Trad. Beatriz Sidou. São Paulo: Centauro, 2006, pp. 71 -111.

KRISTEVA, Júlia. Introdução à Semanálise. Trad. Lúcia Helena Franca Ferraz. São Paulo: Editora perspectiva, 1974.

LIMA, Luiz Costa. A aguarrás do tempo: estudos sobre narrativa. Rio de Janeiro: Rocco, 1989.

MERQUIOR, José Guilherme. Natureza da lírica. In: MERQUIOR, José Guilherme. $A$ Astúcia da Mímese: Ensaios sobre lírica. $2^{a}$ ed. Rio de Janeiro: Topbooks, 1997, pp. 17-33.

MOISÉS, Leyla Perrone. Crítica e intertextualidade. In: MOISÉS, Leyla Perrone. Texto, Crítica, Escritura. Ensaios. São Paulo: Editora Ática, 1978, pp. 58 - 76.

PESSOA, Fernando. António Botto e o ideal estético em Portugal. In: BOTTO, António. As Canções de António Botto. Lisboa: Oficinas Bertrand, 1980, p. 7 - 16.

RICOEUR, Paul. Tempo e Narrativa. Tomo III. Trad. Márcia Valéria Martinez de Aguiar. São Paulo: editora WMF Martins Fontes, 2010. 
Revista .

Desassossegi:

WHITHE, Hayden. Trópicos do discurso: ensaios sobre a crítica da cultura. Trad. Alípio Correia de Franca Neto. São Paulo: EDUSP, 1994.

Artigo recebido em 6 de Fevereiro de 2012 e aprovado em 19 de Abril de 2012 